\title{
EZH2/H3K27Me3 and phosphorylated EZH2 predict chemotherapy response and prognosis in ovarian cancer
}

\author{
Si Sun ${ }^{\text {Equal first author, } 1 \text {, Qiang Yang }}{ }^{\text {Equal first author, }{ }^{1}, \text { E Cai }}{ }^{1}$, Bangxing Huang ${ }^{2}$, Feiquan Ying ${ }^{1}$, Yiping Wen ${ }^{1}$, Jing Cai ${ }^{1}$, Ping \\ Yang ${ }^{\text {Corresp. 1,3 }}$ \\ ${ }^{1}$ Department of Gynecology and Obstetrics, Union Hospital, Tongji Medical College, Huazhong University of Science and Technology, Wuhan 430022, \\ China \\ 2 Department of Pathology, Union Hospital, Tongji Medical College, Huazhong University of Science and Technology, Wuhan 430022, China \\ 3 Department of Obstetrics and Gynecology, First Affiliated Hospital, School of Medicine, Shihezi University, Shihezi, China \\ Corresponding Author: Ping Yang \\ Email address: yangping5127@163.com
}

Background. EZH2 acts as an oncogene through canonical pathway EZH2/H3K27Me3 and uncanonical pathway pAkt1/pS21EZH2 in many solid tumors including ovarian cancer. However, the clinical value of $\mathrm{EZH} 2 / \mathrm{H} 3 \mathrm{~K} 27 \mathrm{Me} 3$ and pAkt1/pS21EZH2 remained unclear. In the current study, we aim to investigate the correlation between these two pathways to clinical-pathological parameters and prognosis.

Methods. EZH2, H3K27Me3, pAkt1 and pS21EZH2 expression were evaluated by tissue micro-array and immunohistochemistry in a cohort of ovarian cancer patients. The results were analyzed based on clinical characteristics and survival outcomes.

Results. EZH2, H3K27Me3, pAkt1 and pS21EZH2 were universally expressed in ovarian cancer specimens with a positive expression rate of $81.54 \%$ (53/65), 88.89\% (48/54), 63.07\% (41/65) and 75.38\% (49/65). EZH2-pS21EZH2 (Spearman $r=0.580, \mathrm{P}<0.0001$ ) and pS21EZH2-pAkt1 (Spearman $r=$ $0.546, \mathrm{P}<0.0001$ ) were closely correlated while EZH2- H3K27Me3 were less closely correlated (Spearman $r=0.307, P=0.002)$. Low pS21EZH2 associated with better chemotherapy response $(\mathrm{OR}=$ $0.184 ; 95 \% \mathrm{Cl}: 0.052-0.647, \mathrm{P}=0.008$ ) according to logistic regression with an area under the curve of 0.789 (specificity $89.36 \%$, sensitivity $68.42 \%$ ) by ROC analysis and predicted improved progression-free survival $(\mathrm{HR}=0.453 ; 95 \% \mathrm{Cl}: 0.229-0.895, \mathrm{P}=0.023)$ as indicated by multivariate cox regression. $\mathrm{A}$ combination of $\mathrm{EZH} 2^{\text {low }} / \mathrm{H} 3 \mathrm{~K} 27 \mathrm{Me} 3^{\text {low }}$ status predicted better chemotherapy response $(\mathrm{OR}=0.110 ; 95 \% \mathrm{Cl}$ : $0.013-0.906, \mathrm{P}=0.040)$ and better progression-free survival $(\mathrm{HR}=0.388 ; 95 \% \mathrm{Cl}: 0.164-0.917, \mathrm{P}=$ 0.031 ). The results suggested that EZH2/H3K27Me3 and pEZH2 predicted chemotherapy response and progression-free survival in ovarian cancer. 
EZH2/H3K27Me3 and phosphorylated EZH2 predict chemotherapy response and prognosis in 2 ovarian cancer

3 Si Sun $^{1 *}$, Qiang Yang ${ }^{1 *}$, E Cai ${ }^{1}$, Bangxing Huang ${ }^{2}$, Feiquan Ying ${ }^{1}$, Yiping Wen ${ }^{1}$, Jing Cai ${ }^{1}$, Ping 4 Yang, 3\#

$5 \quad{ }^{1}$ Department of Gynecology and Obstetrics, Union Hospital, Tongji Medical College, Huazhong 6 University of Science and Technology, Wuhan 430022, China

$7 \quad 2$ Department of Pathology, Union Hospital, Tongji Medical College, Huazhong University of

8 Science and Technology, Wuhan 430022, China

$9{ }^{3}$ Department of Obstetrics and Gynecology, First Affiliated Hospital, School of Medicine,

10 Shihezi University, Shihezi, P.R. China

$11 *$ Si Sun and Qiang Yang contributed equally to this work

12 Corresponding Author:

13 Ping Yang

14 Department of Obstetrics and Gynecology, Union hospital, Tongji Medical College, Huazhong

15 University of Science and Technology, 1277 Jiefang Avenue, Wuhan 430022, P.R. China

16 Department of Obstetrics and Gynecology, First Affiliated Hospital, School of Medicine, Shihezi

17 University, 107 Bei-er Road, Shihezi, P.R. China

18 Email address: yangping5127@163.com

19 Key words: Ovarian cancer, prognosis, chemotherapy response, phosphorylated EZH2

20 Si et al: pEZH2 predicts ovarian cancer prognosis 


\section{Abstract}

22 Background. EZH2 acts as an oncogene through canonical pathway EZH2/H3K27Me3 and uncanonical pathway pAkt1/pS21EZH2 in many solid tumors including ovarian cancer. However, the clinical value of EZH2/H3K27Me3 and pAkt1/pS21EZH2 remained unclear. In the current study, we aim to investigate the correlation between these two pathways to clinical-pathological parameters and prognosis.

Methods. EZH2, H3K27Me3, pAkt1 and pS21EZH2 expression were evaluated by tissue microarray and immunohistochemistry in a cohort of ovarian cancer patients. The results were analyzed based on clinical characteristics and survival outcomes.

Results. EZH2, H3K27Me3, pAkt1 and pS21EZH2 were universally expressed in ovarian cancer specimens with a positive expression rate of $81.54 \%$ (53/65), 88.89\% (48/54), 63.07\% (41/65) and $75.38 \%$ (49/65). EZH2-pS21EZH2 (Spearman $r=0.580, \mathrm{P}<0.0001)$ and pS21EZH2-pAkt1 (Spearman $r=0.546, P<0.0001$ ) were closely correlated while EZH2- H3K27Me3 were less closely correlated (Spearman $\mathrm{r}=0.307, \mathrm{P}=0.002$ ). Low pS21EZH2 associated with better chemotherapy response $(\mathrm{OR}=0.184 ; 95 \% \mathrm{CI}: 0.052-0.647, \mathrm{P}=0.008)$ according to logistic regression with an area under the curve of 0.789 (specificity $89.36 \%$, sensitivity $68.42 \%$ ) by ROC analysis and predicted improved progression-free survival $(\mathrm{HR}=0.453 ; 95 \% \mathrm{CI}: 0.229-0.895, \mathrm{P}$ $=0.023)$ as indicated by multivariate cox regression. A combination of EZH2 $2^{\text {low }} / \mathrm{H} 3 \mathrm{~K} 27 \mathrm{Me} 3^{\text {low }}$ status predicted better chemotherapy response $(\mathrm{OR}=0.110 ; 95 \% \mathrm{CI}: 0.013-0.906, \mathrm{P}=0.040)$ and better progression-free survival $(\mathrm{HR}=0.388 ; 95 \% \mathrm{CI}$ : $0.164-0.917, \mathrm{P}=0.031)$. The results suggested that $\mathrm{EZH} 2 / \mathrm{H} 3 \mathrm{~K} 27 \mathrm{Me} 3$ and $\mathrm{pEZH} 2$ predicted chemotherapy response and progressionfree survival in ovarian cancer.

\section{Introduction}

Ovarian cancer is the most lethal gynecological malignancy (Torre et al., 2018). Cytoreductive surgery combined with platinum based chemotherapy remained primary regimen for ovarian cancer. Resistance to platinum-based chemotherapy was the main cause that leads to chemotherapy failure (Christie and Bowtell, 2017). Promotion of drug research and development aimed to improve the prognosis of ovarian cancer patients was fruitful. Combination of topotecan and Sorafenib significantly increased the progression-free survival in women with platinum-resistant 
51 ovarian cancer (Chekerov et al., 2018). In combination of carboplatin and paclitaxel, Nintedanib

52 increased progression-free survival for advanced ovarian cancer patients (du Bois et al., 2016).

53 Despite the encouraging achievement of the new drugs, the overall survival of ovarian cancer

54 patients was not significantly improved. Customization of appropriate chemotherapy regimen was

55 based on pre-chemotherapy sensitivity prediction. Therefore, pre-chemotherapy prediction for

56 platinum resistance is essential in stratification of patients to different primary chemotherapy in

57 order to avoid treatment delay and strive for more benefit.

58 As the key component of polycomb repressive complex 2 (PRC2), enhancer of zeste homolog 2 (EZH2) contributes to epithelial malignancies through histone modification and epigenetic gene silencing. EZH2 was intimately involved in platinum resistance according to previous studies: EZH2 was overexpressed in cancer stem-like cells enriched by platinum (Wen et al., 2017); EZH2H3K27Me3 axis induced chromatin condensation and SLFN11 gene silencing led to DNA-damage repair deficiency and acquired platinum resistance (Gardner et al., 2017). Generally, EZH2 overexpression is associated with platinum resistance and poor prognosis of epithelial malignancies (Hu et al., 2010; Sun et al., 2018; Yi et al., 2017). However, whether non-canonical EZH2 associated tumorigenic pathway was involved in platinum resistance was still not clear. Non-canonical tumorigenic mechanisms of EZH2 included STAT3/Akt1/pS21EZH2 mediated transcriptional activation and AMPK/pT311EZH2 mediated attenuation of PRC2 dependent H3K27Me3 (Chen et al., 2016; Wan et al., 2018). Previous pathological immune-histochemical analysis reported that higher pT311EZH2 correlated with favorable survival in ovarian cancer patients (Wan et al., 2018). Yet, the clinical implication of pS21EZH2 remained unknown. To further understand the role of canonical and non-canonical EZH2 associated pathways in chemotherapy resistance and prognosis, we investigated the correlation between the key components of two EZH2 pathways EZH2-H3K27Me3 and pAkt1-pS21EZH2 independently and in combination to the clinical outcomes of ovarian cancer patients.

\section{MATERIALS AND METHODS}

\section{Ethics statement}

The study protocol was approved by the Ethical Committee of Union Hospital, Tongji Medical 


\section{Clinical-pathological features}

83 Non-stratified, non-matched clinical and pathological data were retrospectively collected. Basic characteristics included patient age, histology, International Federation of Gynecology and Obstetrics (FIGO) stage, tumor type, treatment regimen, chemotherapy response and follow-up data. Chemotherapy resistance was defined by relapse within six months after completing chemotherapy or progression during the primary chemotherapy. Relapses were diagnosed on clinical symptoms, radiological evidence and biochemical abnormalities such as elevated CA125. Overall survival (OS) was defined as the time from date of diagnosis to death or last follow-up date, progression-free survival (PFS) was defined as the time from surgery to relapse or last followup date. Diagnoses of all patients were confirmed pathologically.

\section{2}

\section{Patient and tumor characteristics}

Tissue samples from a total of 65 patients were obtained from ovarian cancer patients admitted to Union Hospital, Tongji Medical College, Huazhong University of Science and Technology between August 2008 and October 2015. All patients underwent radical surgery followed by standard platinum based chemotherapy. The median age of the patients was $52(32-72)$ years.

\section{Tissue micro-array construction}

65 non-consecutive, unselected primary ovarian cancer specimens were included in the tissue microarray. The tumor samples were collected within one hour after resection from the primary site. Formalin-fixed paraffin-embedded (FFPE) tissue blocks were prepared according to the standard procedure. Tissue cylinders of $2 \mathrm{~mm}$ in diameter were punched from representative areas of each block with regard to the matching H\&E staining control by a MiniCore Control Station (Alphelys Sarl, France). The Selected tissue cylinders were re-arranged and brought into three paraffin blocks by a semi-automated tissue arrayer (Beecher Instruments, Sun Prairie, WI, USA). $4 \mu \mathrm{m}$ section slides were prepared for further use.

\section{Immunohistochemistry}


110 Immunohistochemistry (IHC) was performed as previously described. Briefly, the slides were

111 dewaxed in xylene and went through a serial of descending ethanol to rehydrate. Antigen retrieval

112 was performed through microwave irradiation. Blocking and staining were performed using

113 Histostain Kits (SP9001 and SP9002, ZSGB-Bio, Beijing, China). Primary antibodies for EZH2

114 (1:100, Cell Signaling Technology \#5246, Danvers, USA), pS21EZH2 (1:100, Bethyal \#00388,

115 Montgomery, USA), p S473Akt1 (1:100, Cell Signaling Technology \#4060, Danvers, USA) and

116 H3K27Me3(1:400, Abclonal \#A2363, Boston, USA) and were applied as recommended by the

117 manufacturers. Replacements of primary antibodies by IgG were provided as negative and isotype

118 controls. DAB color development and hematoxylin counterstaining were performed as

119 appropriate.

120

\section{IHC evaluation}

122 IHC evaluation was performed by two trained researchers in a blinded manner, a third pathologist 123 was referred to when disagreement occurred. IHC scores $(0$ - 12) were assessed using a semi124 quantitative scale multiplying the percentage of positive tumor cells $(0,0 \% ; 1,<25 \% ; 2,25 \%$ $12550 \% ; 3,50 \%-75 \% ; 4,>75 \%$ ) by stain intensity ( 0 , negative; 1 , weak; 2 , moderate; 3 , strong). Only 126 nuclear staining was considered valid when measuring the scores for EZH2, H3K27Me3, p-EZH2 127 and p-Akt1. All results were based on five high power (400X) fields.

\section{Statistical analysis}

129 All statistical analyses were performed using SPSS 20.0 software. The association between the 130 IHC scores of EZH2, H3K27Me3, p-Akt1 and p-EZH2 and ovarian cancer clinical pathological

131 characteristics were assessed using chi square, Fisher's exact and Kruskal-Wallis tests. The 132 correlation of EZH2/H3K27Me3 and p-EZH2/p-Akt1 were analyzed using Spearman test. Mann

133 Whitney test was used to compare the difference between two groups as appropriate. Receiver 134 operating characteristic (ROC) curve were plotted to examine the value of EZH2, p-EZH2 and $135 \mathrm{EZH} 2 / \mathrm{H} 3 \mathrm{~K} 27 \mathrm{Me} 3$ combination as predictive factor for chemotherapy response. Logistic and cox 136 regression were used to analyze risks for chemotherapy response and survival. For measurement 137 of chemotherapy response, odds ratio (OR) was used. When OR $>1$, the patients were prone to 138 chemo-resistant; when OR $<1$, the patients were prone to chemo-sensitive. For measurement of 139 OS and PFS, hazard ratio (HR) was used. When HR > 1, the patients were prone to worse outcome; 
140 When HR $<1$, the patients were prone to better outcome. Kaplan-Meier method and log-rank test

141 were used to plot and analyze survival curves. $\mathrm{P}$ values $<0.05$ were considered statistically 142 significant.

\section{RESULTS}

144 Association between EZH2 associated pathways and clinical pathological features.

145 To investigate the association of canonical and non-canonical EZH2 pathways to clinical 146 pathological features, we first investigate each pathway component independently. The 147 components of canonical and non-canonical EZH2 pathways were universally expressed in ovarian 148 cancer specimens with a positive expression rate of 81.54\% (53/65) for EZH2, 88.89\% (48/54) for $149 \mathrm{H} 3 \mathrm{~K} 27 \mathrm{Me} 3,63.07 \%$ (41/65) for pAkt1, and 75.38\% (49/65) for pS21EZH2. EZH2-pS21EZH2 150 (Spearman $\mathrm{r}=0.580, \mathrm{P}<0.0001)$ and $\mathrm{pS} 21 \mathrm{EZH} 2-\mathrm{pAkt1}$ (Spearman $\mathrm{r}=0.546, \mathrm{P}<0.0001)$ were 151 closely correlated while EZH2-H3K27Me3 were less closely correlated (Spearman r $=0.307, \mathrm{P}=$ 152 0.002) (Figure 1). Samples were classified as EZH2 High/Low, H3K27Me3 High/Low, pEZH2 153 High/Low and pAkt1 High/Low groups by the median IHC scores (6 for EZH2, 8.5 for $154 \mathrm{H} 3 \mathrm{~K} 27 \mathrm{Me} 3,6$ for $\mathrm{pS} 21 \mathrm{EZH} 2$ and 2 for $\mathrm{p}-\mathrm{Akt} 1)$. High EZH2 $(\mathrm{P}=0.053)$ and $\mathrm{pEZH} 2(\mathrm{P}=0.011)$ 155 expression were closely related to chemotherapy resistance (Figure 2). Specimens from FIGO 156 stage I-II patients were prone to higher pAkt1 level $(\mathrm{P}=0.097)$. H3K27Me3 IHC score tended to 157 be lower in tissue samples from elderly aged patients $(\mathrm{P}=0.057)$. No significant association was 158 found between EZH2, H3K27Me3, pS21EZH2 or pAkt1 and histology or tumor type (Table 1).

159 In order to assess the clinical relevance of different EZH2 related pathways, we next analyzed 160 clinical pathological features in tissues with different EZH2/H3K27Me3 and pAkt1/pS21EZH2 161 levels. For EZH2-H3K27Me3, samples were classified as EZH2high/H3K27Me ${ }^{\text {high }}$, $162 \mathrm{EZH} 2^{\text {high }} / \mathrm{H} 3 \mathrm{~K} 27 \mathrm{Me} 3^{\text {low }}, \mathrm{EZH} 2^{\text {low }} / \mathrm{H} 3 \mathrm{~K} 27 \mathrm{Me} 3^{\text {high }}$ and $\mathrm{EZH} 2^{\text {low }} / \mathrm{H} 3 \mathrm{~K} 27 \mathrm{Me} 3^{\text {low }}$. For pAkt1$163 \mathrm{pS} 21 \mathrm{EZH} 2$, samples were classified as $\mathrm{pAkt} 1^{\text {high}} / \mathrm{pEZH} 2^{\text {high }}$, $\mathrm{pAkt} 1^{\text {high }} / \mathrm{pEZH} 2^{\text {low }}$, $164 \mathrm{pAkt} 1^{\text {low }} / \mathrm{pEZH} 2^{\text {high }}$ and $\mathrm{pAkt} 1^{\text {low }} / \mathrm{pEZH} 2^{\text {low }}$. The distribution of number of cases in each group 165 were compared in relation to clinical features including age, histology, FIGO stage, tumor type 166 and chemo-response. The results suggested that EZH2/H3K27Me3 level $(\mathrm{P}=0.053)$ and $167 \mathrm{pAkt1} / \mathrm{pEZH} 2$ level $(\mathrm{P}=0.025)$ were closely correlated with chemotherapy response (Table 2 and $1683)$. 
170 EZH2/H3K27Me3 and pS21EZH2 predicted platinum-based chemotherapy response.

171 As both EZH2/H3K27Me3 and pAkt1/pS21EZH2 pathways correlated with chemotherapy

172 response, subsequent assessment of the prognostic value of these two pathways were performed.

173 First, the prognostic value of independent EZH2, H3K27Me3, pS21EZH2 and pAkt1 for

174 chemotherapy response was assessed by logistic regression and ROC analysis. Logistic regression

175 revealed that patients with lower $\mathrm{pS} 21 \mathrm{EZH} 2(\mathrm{OR}=0.184 ; 95 \% \mathrm{CI}: 0.052-0.647, \mathrm{P}=0.008)$ and

176 lower EZH2 (OR = 0.095; 95\%CI: 0.948 - 10.107, P = 0.061) IHC scores had better chemotherapy

177 response (Table 4). The area under the curve (AUC) for EZH2 and pS21EHZ2 were 0.688

178 (specificity 74.47\%, sensitivity 63.16\%) and 0.789 (specificity $89.36 \%$, sensitivity 68.42\%)

179 (Figure 2). Although H3K27Me3 and pAkt1 did not have significant prognostic value as single

180 factors, combined with EZH2 and pS21EZH2, EZH2 $2^{\text {low }} / \mathrm{H} 3 \mathrm{~K} 27 \mathrm{Me} 3^{\text {low }}(\mathrm{OR}=0.110 ; 95 \% \mathrm{CI}$ :

$1810.013-0.906 .107, \mathrm{P}=0.040)$ and $\mathrm{pAkt1}{ }^{\mathrm{low}} / \mathrm{pEZH} 2^{\text {low }}(\mathrm{OR}=0.260 ; 95 \% \mathrm{CI}: 0.066-1.023, \mathrm{P}=$

1820.054 ) status predicted better chemotherapy response (Table 4). For patients with serous ovarian

183 cancer, pS21EZH2 remained prognostic for chemotherapy response $(\mathrm{OR}=0.188$; 95\%CI: 0.050

$184-0.705, \mathrm{P}=0.013)$. Patients with $\mathrm{EZH} 2^{\text {low }} / \mathrm{H} 3 \mathrm{~K} 27 \mathrm{Me} 3^{\text {low }}(\mathrm{OR}=0.133 ; 95 \% \mathrm{CI}: 0.016-1.133, \mathrm{P}$

$185=0.065)$ and $\mathrm{pAkt} 1^{\mathrm{low}} / \mathrm{pEZH} 2^{\text {low }}(\mathrm{OR}=0.288 ; 95 \% \mathrm{CI}: 0.070-1.190, \mathrm{P}=0.086)$ were prone to

186 better chemotherapy response (Table 5).

187 EZH2/H3K27Me3 and pS21EZH2 predicted PFS in ovarian cancer patients.

188 Since chemotherapy response is an independent factor influencing prognosis, we next evaluate

189 whether EZH2 associated pathways representing varied chemotherapy response status were of

190 prognostic significance to survival of ovarian cancer patients. In all the factors included for

191 analysis, Advanced FIGO stage and poor chemotherapy response were closely related with poorer

192 OS and PFS through both uni- and multi-variate analyses (Table 6 and 7). Kaplan-Meier survival

193 analysis and univariate cox regression analysis for OS revealed that lower EZH2 $(\mathrm{HR}=0.464$;

$19495 \% \mathrm{CI}: 0.205-1.048, \mathrm{P}=0.065)$ and pS21EZH2 $(\mathrm{HR}=0.464 ; 95 \% \mathrm{CI}: 0.206-1.046, \mathrm{P}=0.064)$

195 staining tended to correlate with longer OS. A combination of EZH2 $2^{\text {low }} / \mathrm{H} 3 \mathrm{~K} 27 \mathrm{Me} 3^{\text {low }}$ staining

196 was significantly associated with improved OS $(\mathrm{HR}=0.257 ; 95 \% \mathrm{CI}: 0.076-0.863, \mathrm{P}=0.028)$.

197 Kaplan-Meier survival analysis and univariate cox regression analysis for PFS revealed that lower 198 pS21EZH2 staining was significantly associated with longer PFS (HR = 0.477; 95\%CI: $0.226-$ 
$1990.882, \mathrm{P}=0.020)$. Similarly, a combination of $\mathrm{EZH} 2^{\text {low }} / \mathrm{H} 3 \mathrm{~K} 27 \mathrm{Me} 3^{\text {low }}$ staining was significantly

200 associated with increased PFS (HR $=0.344$; 95\%CI: $0.145-0.813, \mathrm{P}=0.015)$ (Figure 3). When

201 adjusted for FIGO stage, multivariate Cox regression analysis for PFS revealed that pS21EZH2

202 staining $(\mathrm{HR}=0.453 ; 95 \% \mathrm{CI}: 0.229-0.895, \mathrm{P}=0.023)$ and $\mathrm{EZH} 2^{\text {low }} / \mathrm{H} 3 \mathrm{~K} 27 \mathrm{Me} 3^{\text {low }}$ status $(\mathrm{HR}$

$203=0.388 ; 95 \% \mathrm{CI}: 0.164-0.917, \mathrm{P}=0.031)$ remained to be independent prognostic factors for PFS.

204 For patients with serous ovarian cancer, chemotherapy response was closely related with OS and

205 PFS through univariate analyses. Lower pS21EZH2 staining (HR $=0.431 ; 95 \%$ CI: $0.207-0.896$,

$206 \mathrm{P}=0.024)$ and $\mathrm{pAkt1}$ low/pEZH2 ${ }^{\text {low }}$ status $(\mathrm{HR}=0.479 ; 95 \% \mathrm{CI}: 0.219-1.046, \mathrm{P}=0.065)$ were

207 associated with improved PFS (Table 8). We did not found significant relation of age, histology,

208 tumor type, H3K27Me3 expression and pAkt1 expression to OS or PFS through uni- or multi209 variate analyses.

210 DISCUSSION

211 In the present study, we investigated the prognostic value of canonical pathway EZH2/H3K27me3

212 and non-canonical pathway pAkt1/pS21EZH2 of EZH2 in ovarian cancer. We first assessed the 213 association of independent EZH2, H3K27me3, pAkt1, pS21EZH2 and EZH2/H3K27me3,

$214 \mathrm{pAkt1} / \mathrm{pS} 21 \mathrm{EZH} 2$ combination with clinical characteristics of ovarian cancer patients such as age,

215 histology, FIGO stage, tumor type and chemotherapy response. Then the correlation of the above

216 key components of two EZH2 pathways EZH2/H3K27Me3 and pAkt1/pS21EZH2 to

217 chemotherapy response, OS and PFS of ovarian cancer patients were assessed independently and

218 in combination. We observed that $\mathrm{EZH} 2^{\text {low }} / \mathrm{H} 3 \mathrm{~K} 27 \mathrm{Me} 3^{\text {low }}$ predicted better chemotherapy

219 response, OS and PFS while low pS21EZH2 predicted poor chemotherapy response and PFS. The

220 results suggested that both canonical and non-canonical EZH2 pathways contributed to

221 chemotherapy resistance that affected prognosis.

222 Histone methylation is a reversible process subjected to demethylation or acetylation that regulates

223 chromatin configuration and gene expression. Targeting histone methylation transferase EZH2

224 was a promising way to regulate histone modification H3K27me3 status and its gene-inhibiting

225 function. According to current evidence, the effect of EZH2-H3K27me3 pathway to platinum

226 resistance was heterogeneous in different cancer types: EZH2/H3K27me3 contributes to platinum

227 resistance in ovarian cancer, cervical cancer, colorectal cancer, lung cancer and gastric cancer 
228 while sensitizing osteosarcoma and lymphoma to platinum treatment. Several possible 229 mechanisms of EZH2 regulation of response to platinum chemotherapy were discovered so far.

230 Enrichment of EZH2/H3K27me3 at promoter region of intrinsic apoptosis pathways (Caspase-9, $231 \mathrm{p} 53, \mathrm{Bcl} 2$ and Bax) and extrinsic apoptosis pathways (Fas) interfered the integrity of platinum 232 induced apoptotic function and proper response to platinum treatment (Benard et al., 2014). In 233 addition to apoptosis, $\mathrm{EZH} 2 / \mathrm{H} 3 \mathrm{~K} 27 \mathrm{me} 3$ pathway was also reported to negatively regulate 234 autophagy pathway (Sun et al., 2016). Another possible mechanism was that inhibition of Dicer 235 function by EZH2 lead to disordered miRNA function (Cai et al., 2016).

236 Canonical way of targeting EZH2 was primarily through molecular inhibitors such as DZNEP and 237 GSK126. Mounting evidence suggested that EZH2 phosphorylation was involved in reprogram of 238 H3K27Me3 profile and transcriptional activation. EZH2 phosphorylation at S21 by Akt1 impeded 239 EZH2-H3 interaction leading to de-repression of silenced genes (Cha et al., 2005). EZH2 240 phosphorylation at T487 disrupted EZH2 binding with SUZ12 and EED, thereby inhibition of 241 EZH2 methyltransferase activity (Wei et al., 2011). EZH2 phosphorylation at T311 by AMPK 242 disrupted EZH2-SUZ12 interaction attenuated H3K27Me3. EZH2 phosphorylation at T372 by 243 TNF-activated p38 $\alpha$ kinase promoted YY1-EZH2 interaction leading to the formation of 244 repressive chromatin (Palacios et al., 2010). EZH2 phosphorylation at T350 contributed to the 245 recruitment of EZH2 to EZH2-loci and maintenance of H3K27Me3 level (Chen et al., 2010). 246 EZH2 phosphorylation at T345 by CDK1 increased EZH2-HOTAIR interaction (Kaneko et al., 247 2010). EZH2 phosphorylation at T345 and T487 by CDK1 promoted EZH2 ubiquitination and 248 subsequent proteasomal degradation (Wu and Zhang, 2011).

249 To date, very few studies investigated the clinical implication of phosphorylated EZH2. Based on 250 current evidence, the clinical effect of phosphorylated EZH2 was residue-specific. A recent study 251 reported that EZH2 phosphorylation at $\mathrm{T} 372$ reduced ovarian cancer cell proliferation, migration 252 and tumor formation (Wan et al., 2018). The levels of EZH2-T372 phosphorylation in primary 253 ovarian tumor samples were significantly lower than that in normal ovarian surface epithelium 254 (Ozes et al., 2018). Wan et al reported that EZH2 phosphorylation at T311 by AMPK suppressed 255 PRC2 activity and EZH2-pT311 correlated with better survival in ovarian and breast cancer 256 patients (Wan et al., 2018). These results suggested that certain residue phosphorylation such as 
257 T311 and T372 antagonized PRC2 oncogenic effect by disrupting PRC2 complex and played a 258 role as favorable prognostic factors. On the other hand, our results revealed that EZH2 259 phosphorylation at S21 associated with chemotherapy resistance and predicted poor PFS in ovarian 260 cancer patients suggesting an oncogenic role of EZH2-pS21.

261 Ovarian cancer is a heterogeneous disease classified as several histology subtypes characterized

262 by different molecular and biological features. In this study, we performed stratification analysis

263 for chemotherapy response, OS and PFS within the serous ovarian cancer group in addition to 264 general analysis. Low pS21EZH2 status remained predictive for better chemotherapy response and 265 PFS. EZH2 $2^{\text {low }} / \mathrm{H} 3 \mathrm{~K} 27 \mathrm{Me} 3^{\text {low }}$ also showed predictive value regarding chemotherapy response 266 although statistical analysis did not reach significant difference. While EZH2 and pS21EZH2 had 267 inseparable correlation, $\mathrm{pS} 21 \mathrm{EZH} 2$ was only positive in samples with positive EZH2. To 268 investigate whether the predictive value of pS21EZH2 was EZH2 dependent, two different 269 pathways were analyzed. EZH2/H3K27me3 combination provided better prognostic value than 270 EZH2 alone while combination of pAkt1 and pS21-EZH2 was no gain. Considering that pAkt1 is 271 a powerful multi-functional signal transducer regulating numerous pathways, the effect of other 272 pAkt1 associated pathways might have some influence while evaluating pAkt1/pS21EZH2 273 pathway. Therefore, further cellular experiments were needed to elucidate the issue. Due to the 274 limitation of number of cases included, the study only stratified the patients into serous/other 275 groups failing to perform further analysis in other subtypes. Further studies with larger cohort 276 might provide a more consolidate insight.

\section{Conclusions}

278 In conclusion, this study suggested that EZH2/H3K27Me3 and pEZH2 predicted chemotherapy 279 response and progression-free survival in ovarian cancer.

\section{Acknowledgements}

281 We thanked all recruited patients for providing tissue samples. We thanked the staff and graduates

282 from Department of Gynecology and Obstetrics, Union Hospital, Tongji Medical College, 283 Huazhong University of Science and Technology for sample collection. 


\section{Funding}

285 This work was supported by National Natural Science Foundation of China (81572572, 81702570

286 and 81702575), Scientific and Technological Research Projects of Xinjiang Production and 287 Construction Corp (2017DB012) and Union Hospital Scientific Research Fund (2018-229).

\section{Availability of data and materials}

All data generated or analyzed during the present study are included in this article.

290

291

292

293

294

295

296

297

298

299

300

301

302

303

304

305

306

307

\section{Author's contributions}

Ping Yang supervised the project. Jing Cai designed the present study. Si Sun and E Cai performed the experiments. Qiang Yang and Feiquan Ying collected data. Si Sun, Qiang Yang and Yiping Wen interpreted the data. Si Sun, Qiang Yang and Jing Cai prepared the manuscript. All authors contributed to producing the manuscript and approved the final manuscript.

\section{Ethics approved and consent to participate}

The study protocol was approved by the Ethics Committee of Tongji Medical College, Huazhong University of Science and Technology (IOGR No: IORG0003571). Waiver of documentation of informed consent was approved.

\section{Consent for publication}

All authors have agreed the submission of this manuscript.

\section{Competing interests}

The authors declare no competing interests.

\section{REFERENCE}

Benard A, Janssen CM, van den Elsen PJ, van Eggermond MC, Hoon DS, van de Velde CJ, and Kuppen PJ. 2014. Chromatin status of apoptosis genes correlates with sensitivity to chemo-, immune- and radiation therapy in colorectal cancer cell lines. Apoptosis 19:1769-1778. 10.1007/s 10495-014-1042-8 
308 Cai L, Wang Z, and Liu D. 2016. Interference with endogenous EZH2 reverses the

309 chemotherapy drug resistance in cervical cancer cells partly by up-regulating Dicer expression.

310 Tumour Biol 37:6359-6369. 10.1007/s13277-015-4416-9

311 Cha TL, Zhou BP, Xia W, Wu Y, Yang CC, Chen CT, Ping B, Otte AP, and Hung MC. 2005.

312 Akt-mediated phosphorylation of EZH2 suppresses methylation of lysine 27 in histone H3.

313 Science 310:306-310. 10.1126/science.1118947

314 Chekerov R, Hilpert F, Mahner S, El-Balat A, Harter P, De Gregorio N, Fridrich C, Markmann

315 S, Potenberg J, Lorenz R, Oskay-Oezcelik G, Schmidt M, Krabisch P, Lueck HJ, Richter R,

316 Braicu EI, du Bois A, Sehouli J, Noggo, and Investigators AT. 2018. Sorafenib plus topotecan

317 versus placebo plus topotecan for platinum-resistant ovarian cancer (TRIAS): a multicentre,

318 randomised, double-blind, placebo-controlled, phase 2 trial. Lancet Oncol 19:1247-1258.

319 10.1016/S1470-2045(18)30372-3

320 Chen S, Bohrer LR, Rai AN, Pan Y, Gan L, Zhou X, Bagchi A, Simon JA, and Huang H. 2010.

321 Cyclin-dependent kinases regulate epigenetic gene silencing through phosphorylation of EZH2.

322 Nat Cell Biol 12:1108-1114. 10.1038/ncb2116

323 Chen X, Hao A, Li X, Du Z, Li H, Wang H, Yang H, and Fang Z. 2016. Melatonin inhibits

324 tumorigenicity of glioblastoma stem-like cells via the AKT-EZH2-STAT3 signaling axis. J

325 Pineal Res 61:208-217. 10.1111/jpi.12341

326 Christie EL, and Bowtell DDL. 2017. Acquired chemotherapy resistance in ovarian cancer. Ann

327 Oncol 28:viii13-viii15. 10.1093/annonc/mdx446

328 du Bois A, Kristensen G, Ray-Coquard I, Reuss A, Pignata S, Colombo N, Denison U, Vergote I,

329 Del Campo JM, Ottevanger P, Heubner M, Minarik T, Sevin E, de Gregorio N, Bidzinski M,

330 Pfisterer J, Malander S, Hilpert F, Mirza MR, Scambia G, Meier W, Nicoletto MO, Bjorge L,

331 Lortholary A, Sailer MO, Merger M, Harter P, and Consortium AGOSGlGCIENoGOTGI. 2016.

332 Standard first-line chemotherapy with or without nintedanib for advanced ovarian cancer (AGO-

333 OVAR 12): a randomised, double-blind, placebo-controlled phase 3 trial. Lancet Oncol 17:78-

334 89. 10.1016/S1470-2045(15)00366-6

335 Gardner EE, Lok BH, Schneeberger VE, Desmeules P, Miles LA, Arnold PK, Ni A, Khodos I, 336 de Stanchina E, Nguyen T, Sage J, Campbell JE, Ribich S, Rekhtman N, Dowlati A, Massion PP, 
337 Rudin CM, and Poirier JT. 2017. Chemosensitive Relapse in Small Cell Lung Cancer Proceeds

338 through an EZH2-SLFN11 Axis. Cancer Cell 31:286-299. 10.1016/j.ccell.2017.01.006

$339 \mathrm{Hu}$ S, Yu L, Li Z, Shen Y, Wang J, Cai J, Xiao L, and Wang Z. 2010. Overexpression of EZH2

340 contributes to acquired cisplatin resistance in ovarian cancer cells in vitro and in vivo. Cancer

341 Biol Ther 10:788-795. 10.4161/cbt.10.8.12913

342 Kaneko S, Li G, Son J, Xu CF, Margueron R, Neubert TA, and Reinberg D. 2010.

343 Phosphorylation of the PRC2 component Ezh2 is cell cycle-regulated and up-regulates its

344 binding to ncRNA. Genes Dev 24:2615-2620. 10.1101/gad.1983810

345 Ozes AR, Pulliam N, Ertosun MG, Yilmaz O, Tang J, Copuroglu E, Matei D, Ozes ON, and

346 Nephew KP. 2018. Protein kinase A-mediated phosphorylation regulates STAT3 activation and

347 oncogenic EZH2 activity. Oncogene 37:3589-3600. 10.1038/s41388-018-0218-z

348 Palacios D, Mozzetta C, Consalvi S, Caretti G, Saccone V, Proserpio V, Marquez VE, Valente S,

349 Mai A, Forcales SV, Sartorelli V, and Puri PL. 2010. TNF/p38alpha/polycomb signaling to Pax7

350 locus in satellite cells links inflammation to the epigenetic control of muscle regeneration. Cell

351 Stem Cell 7:455-469. 10.1016/j.stem.2010.08.013

352 Sun S, Zhao S, Yang Q, Wang W, Cai E, Wen Y, Yu L, Wang Z, and Cai J. 2018. Enhancer of

353 zeste homolog 2 promotes cisplatin resistance by reducing cellular platinum accumulation.

354 Cancer Sci 109:1853-1864. 10.1111/cas.13599

355 Sun Y, Jin L, Liu JH, Sui YX, Han LL, and Shen XL. 2016. Interfering EZH2 Expression

356 Reverses the Cisplatin Resistance in Human Ovarian Cancer by Inhibiting Autophagy. Cancer

357 Biother Radiopharm 31:246-252. 10.1089/cbr.2016.2034

358 Torre LA, Trabert B, DeSantis CE, Miller KD, Samimi G, Runowicz CD, Gaudet MM, Jemal A,

359 and Siegel RL. 2018. Ovarian cancer statistics, 2018. CA Cancer J Clin 68:284-296.

$360 \quad 10.3322 /$ caac. 21456

361 Wan L, Xu K, Wei Y, Zhang J, Han T, Fry C, Zhang Z, Wang YV, Huang L, Yuan M, Xia W,

362 Chang WC, Huang WC, Liu CL, Chang YC, Liu J, Wu Y, Jin VX, Dai X, Guo J, Liu J, Jiang S,

363 Li J, Asara JM, Brown M, Hung MC, and Wei W. 2018. Phosphorylation of EZH2 by AMPK

364 Suppresses PRC2 Methyltransferase Activity and Oncogenic Function. Mol Cell 69:279-291

365 e275. 10.1016/j.molcel.2017.12.024 
366 Wei Y, Chen YH, Li LY, Lang J, Yeh SP, Shi B, Yang CC, Yang JY, Lin CY, Lai CC, and

367 Hung MC. 2011. CDK1-dependent phosphorylation of EZH2 suppresses methylation of H3K27

368 and promotes osteogenic differentiation of human mesenchymal stem cells. Nat Cell Biol 13:87-

369 94. 10.1038/ncb2139

370 Wen Y, Hou Y, Huang Z, Cai J, and Wang Z. 2017. SOX2 is required to maintain cancer stem

371 cells in ovarian cancer. Cancer Sci 108:719-731. 10.1111/cas.13186

372 Wu SC, and Zhang Y. 2011. Cyclin-dependent kinase 1 (CDK1)-mediated phosphorylation of

373 enhancer of zeste 2 (Ezh2) regulates its stability. J Biol Chem 286:28511-28519.

374 10.1074/jbc.M111.240515

375 Yi X, Guo J, Guo J, Sun S, Yang P, Wang J, Li Y, Xie L, Cai J, and Wang Z. 2017. EZH2-

376 mediated epigenetic silencing of TIMP2 promotes ovarian cancer migration and invasion. Sci

377 Rep 7:3568. 10.1038/s41598-017-03362-z 
379 Figure 1. General expression of EZH2/H3K27Me3 and pAkt1/pEZH2 in ovarian cancer. (A-D)

380 Representative images of EZH2, H3K27Me3, pAkt1 and pEZH2 staining in ovarian cancer tissue 381 (mainly stained in nucleus). $40 \times$ and $200 \times(\mathrm{E})$ and $(\mathrm{F})$ Positive correlation between the IHC score 382 of pAkt1 with pEZH2 and EZH2 with H3K27Me3 (Spearman's correlation test).

383 Figure 2. pEZH2 predicted chemotherapy response in ovarian cancer. (A) The corresponding 384 histogram of semi-quantification of pEZH2 level in resistant and sensitive groups. Mann Whitney 385 test, $\mathrm{P}<0.001$. (B) ROC curves of EZH2, $\mathrm{pEZH} 2$, the combination of $\mathrm{EZH} 2_{\mathrm{low}} / \mathrm{H} 3 \mathrm{~K} 27 \mathrm{Me} 3_{\text {low }}$ and 386 the combination of $\mathrm{pAkt} 1_{\text {low }} / \mathrm{pEZH} 2_{\text {low }} \cdot \mathrm{AUC}_{\mathrm{EZH} 2}=0.688, \quad \mathrm{AUC}_{\mathrm{pEZH} 2}=0.789, \mathrm{AUC}$ 387 EZH2low/H3K27Me3low $=0.6461, \mathrm{AUC}_{\mathrm{pAkt1low} / \mathrm{pEZH} 2 \mathrm{low}}=0.6341$.

388 Figure 3. pEZH2 and EZH2/H3K27Me3 predicted prognosis in ovarian cancer. (A-F) Kaplan389 Meier plots for overall survival and progression-free survival in ovarian cancer patients with 390 different pEZH2 (A and B), EZH2 (C and D) and EZH2/H3K27Me3 (E and F) level. 


\section{Figure 1}

General expression of EZH2/H3K27Me3 and pAkt1/pEZH2 in ovarian cancer.

(A-D) Representative images of EZH2, H3K27Me3, pAkt1 and pEZH2 staining in ovarian cancer tissue (mainly stained in nucleus). $40 \times$ and $200 \times(E)$ and (F) Positive correlation between the IHC score of pAkt1 with pEZH2 and EZH2 with H3K27Me3 (Spearman's correlation test). 
A

p-EZH2

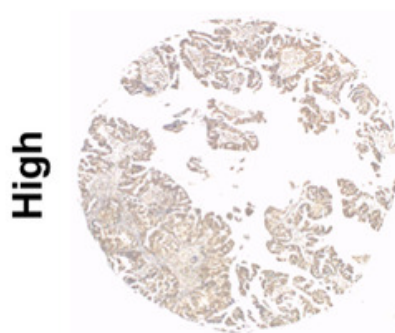

C
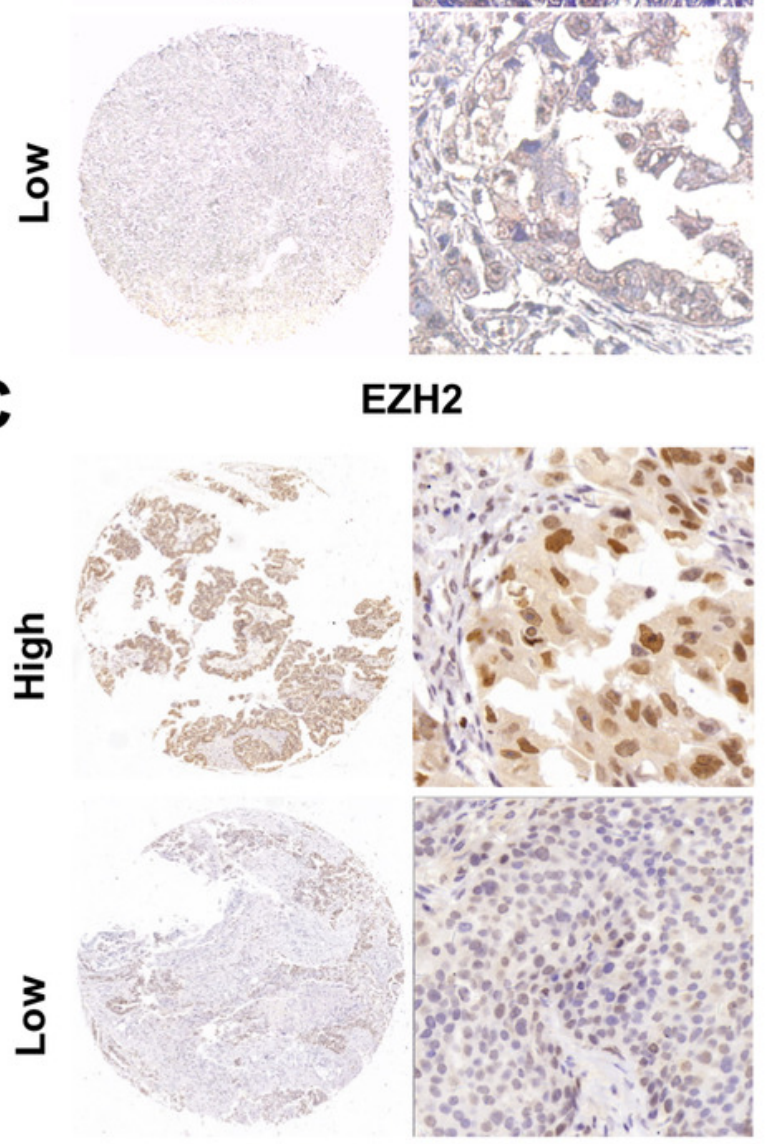

E

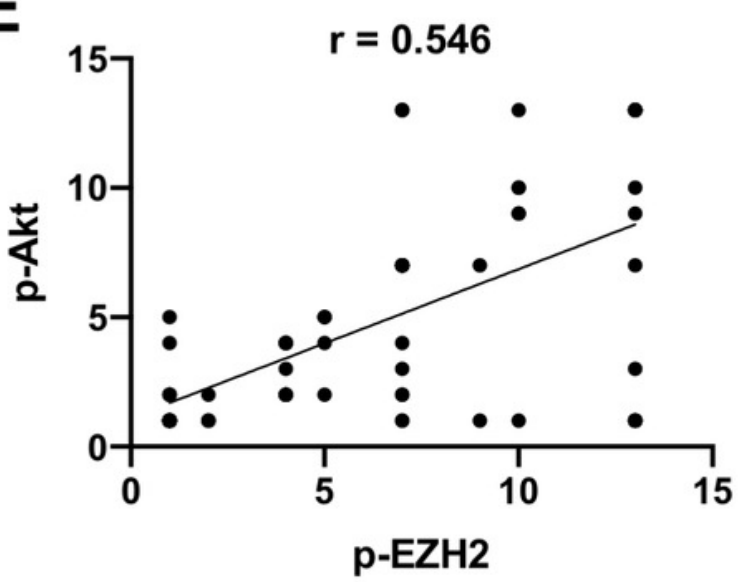

B p-Akt1
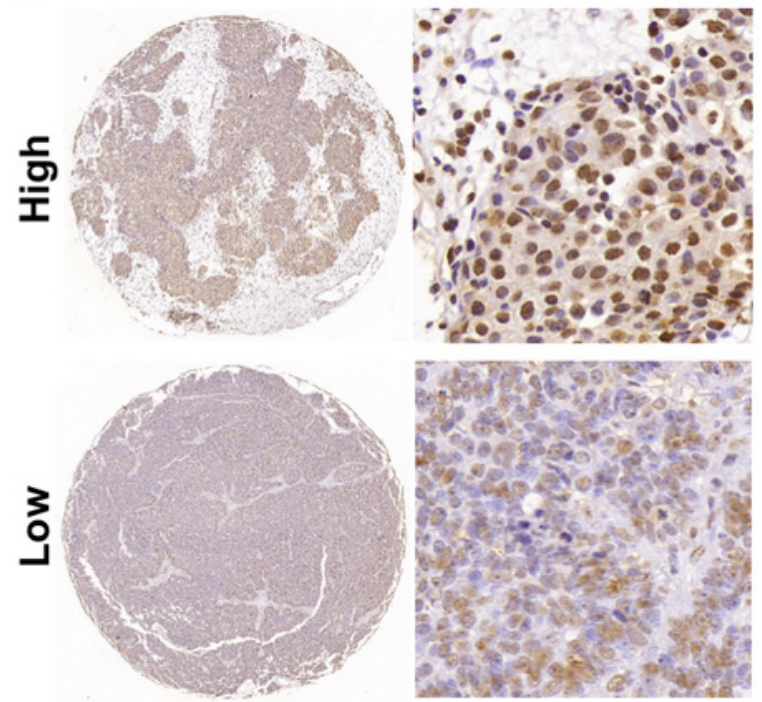

D

H3K27Me3
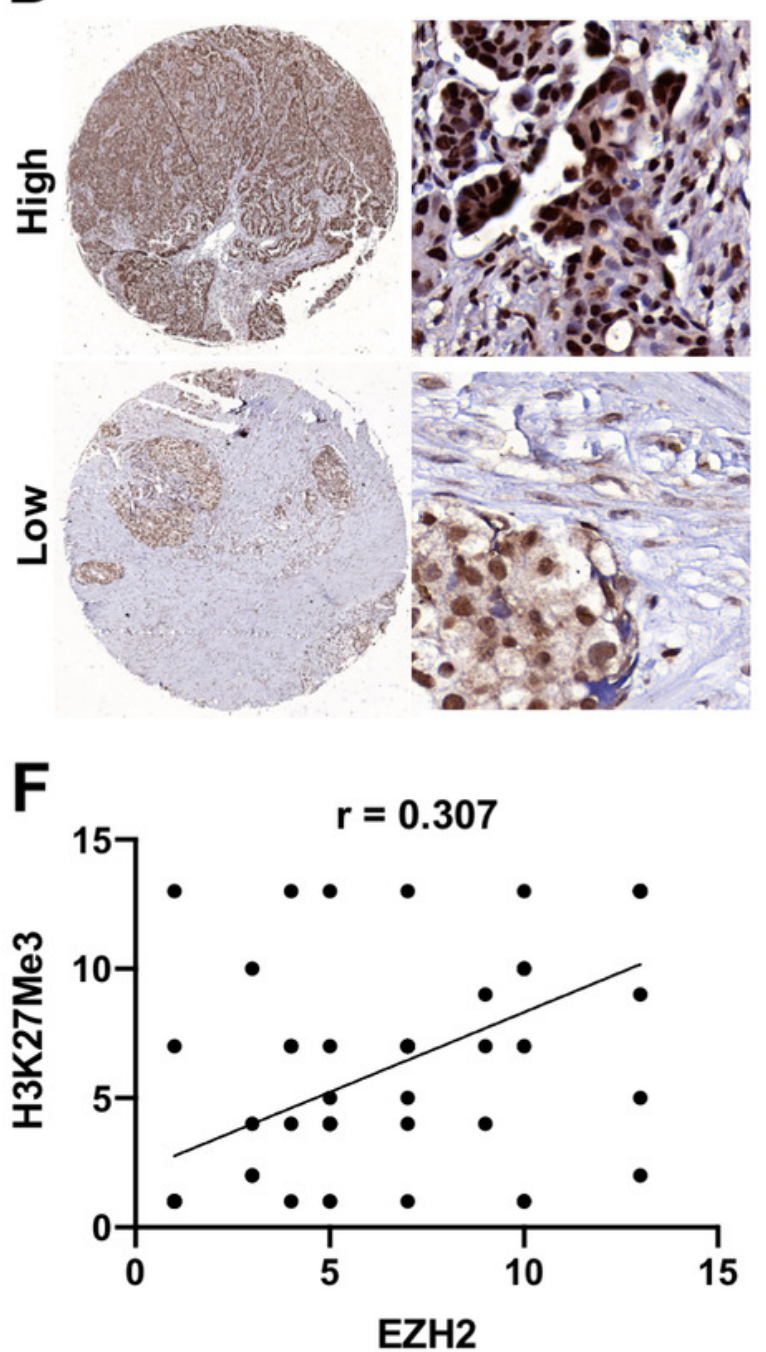
Figure 2

pEZH2 predicted chemotherapy response in ovarian cancer.

(A) The corresponding histogram of semi-quantification of pEZH2 level in resistant and sensitive groups. Mann Whitney test, $\mathrm{P}<0.001$. (B) ROC curves of EZH2, $\mathrm{pEZH} 2$, the combination of EZH2low/H3K27Me3low and the combination of pAkt1low/pEZH2low.

AUCEZH2 $=0.688$, AUCpEZH2 $=0.789$, AUC EZH2low/H3K27Me3low $=0.6461$, AUCpAkt1low/pEZH2low $=0.6341$.
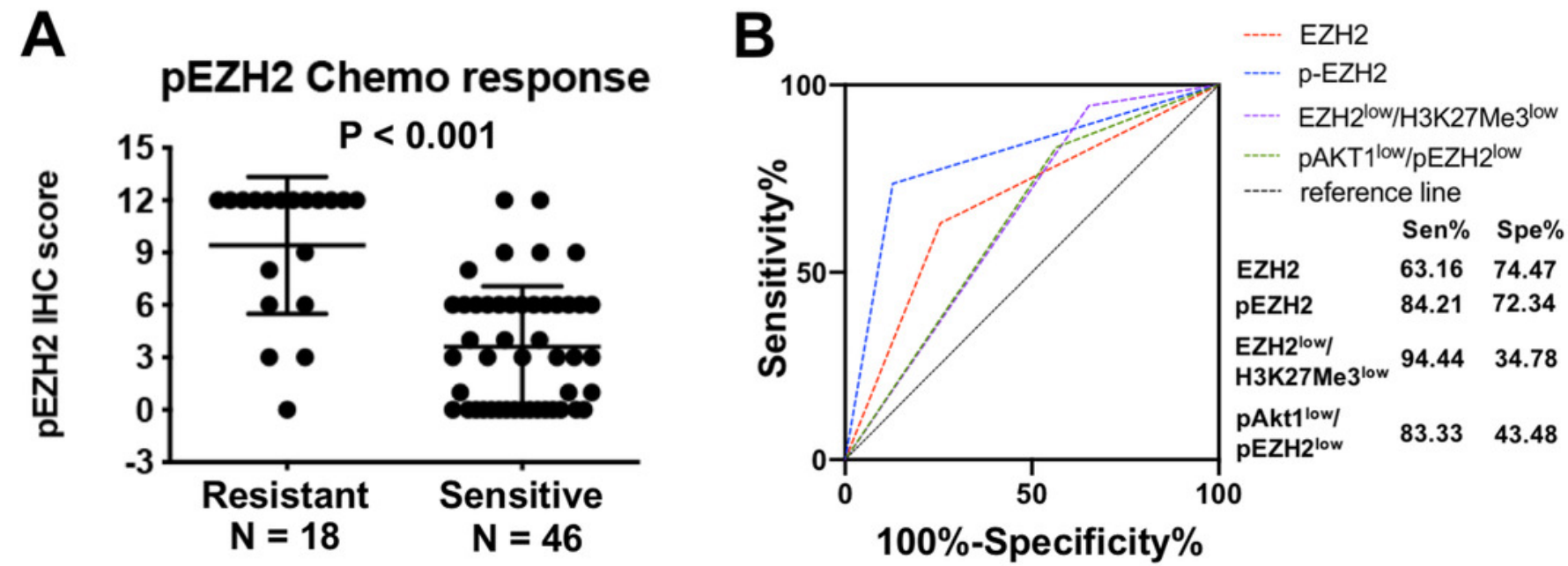
Figure 3

pEZH2 and EZH2/H3K27Me3 predicted prognosis in ovarian cancer.

(A-F) Kaplan-Meier plots for overall survival and progression-free survival in ovarian cancer patients with different pEZH2 (A and B), EZH2 ( $C$ and $D)$ and EZH2/H3K27Me3 (E and F) level. 
A

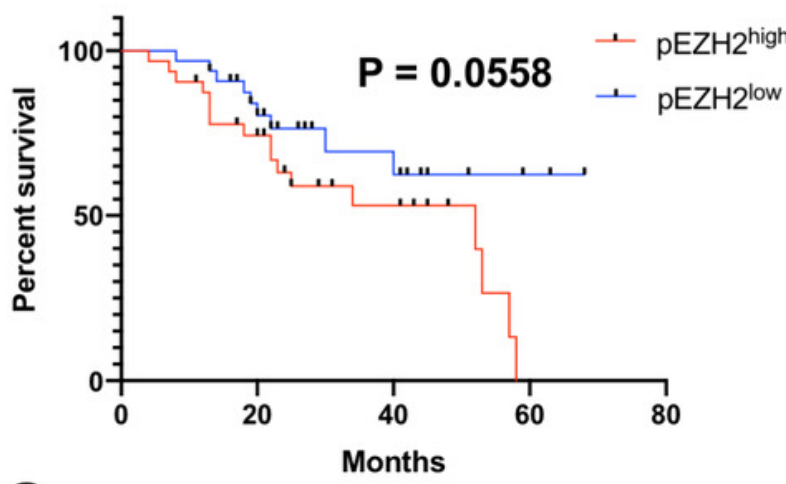

C

Overall survival

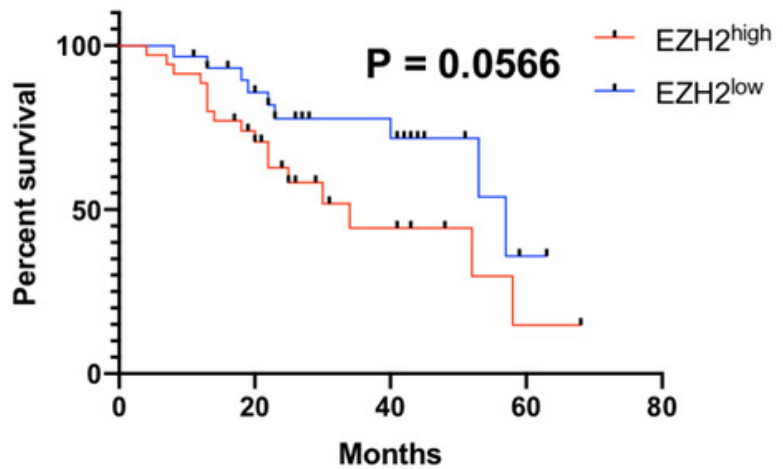

E

Overall survival

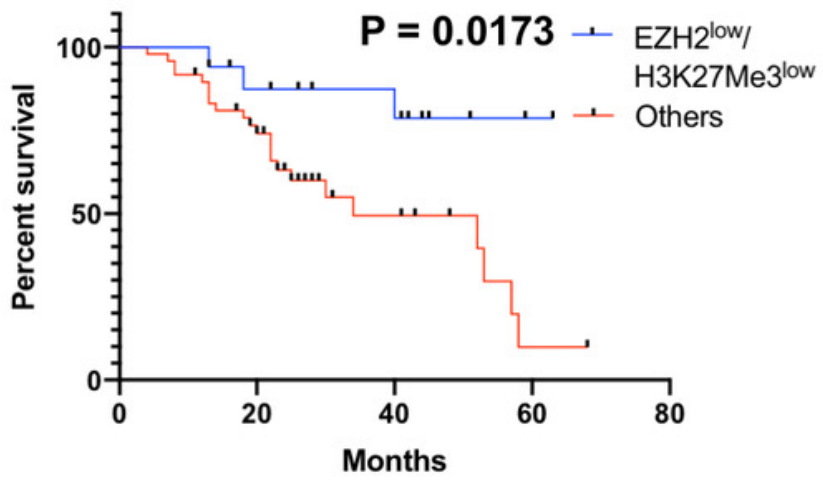

B Progression-free survival

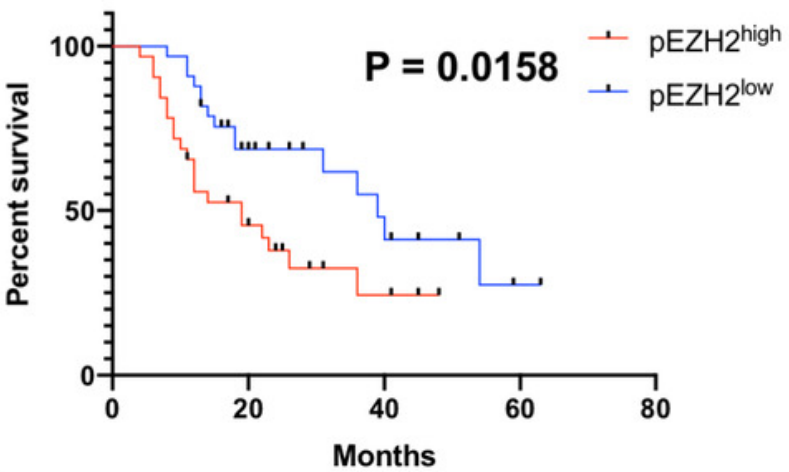

D

Progression-free survival

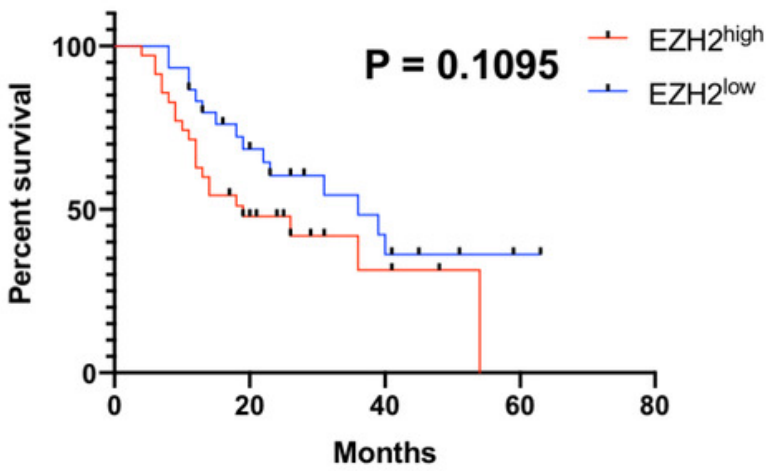

F

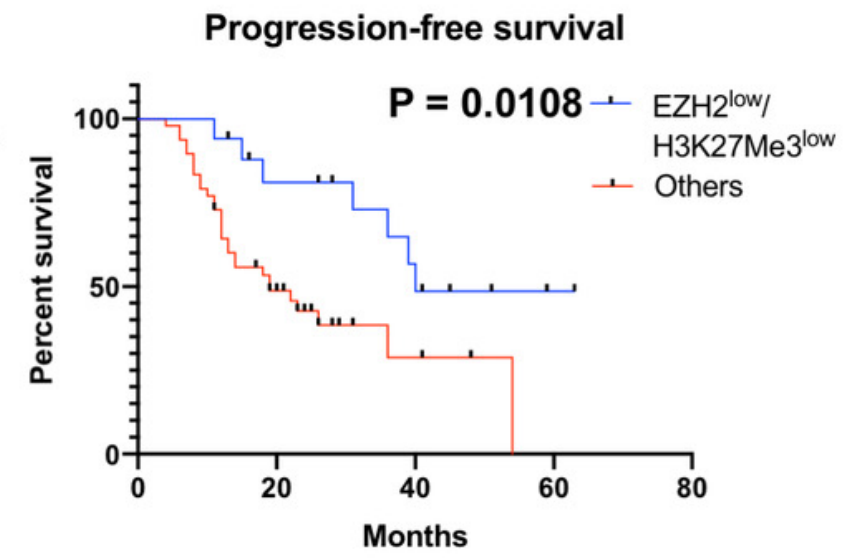




\section{Table $\mathbf{1}$ (on next page)}

Association between pEZH2, pAkt1, EZH2 and H3K27Me3 to clinical pathological features in ovarian cancer by IHC-score stratification. 
1 Table1. Association between pEZH2, pAkt1, EZH2 and H3K27Me3 to clinical pathological features in ovarian cancer by IHC-score

2 stratification*.

\begin{tabular}{|c|c|c|c|c|c|c|c|c|c|c|c|c|c|c|}
\hline \multirow{2}{*}{$\begin{array}{c}\text { Clinicopathological } \\
\text { Features }\end{array}$} & \multirow[t]{2}{*}{$\mathrm{N}$} & \multicolumn{3}{|c|}{$\mathrm{pEZH} 2$} & \multicolumn{3}{|c|}{ pAkt1 } & \multicolumn{3}{|c|}{ EHZ2 } & \multirow[t]{2}{*}{$\mathrm{N}$} & \multicolumn{3}{|c|}{$\mathrm{H} 3 \mathrm{~K} 27 \mathrm{Me} 3$} \\
\hline & & High & Low & $\mathrm{P}$ & High & Low & $\mathrm{P}$ & High & Low & $\mathrm{P}$ & & High & Low & $\mathrm{P}$ \\
\hline \multicolumn{15}{|l|}{ Age (years) ${ }^{* *}$} \\
\hline$<50$ & 27 & 13 & 14 & 0.883 & 16 & 11 & 0.213 & 15 & 12 & 1.000 & 23 & 16 & 7 & 0.057 \\
\hline$\geq 50$ & 38 & 19 & 19 & & 16 & 22 & & 20 & 18 & & 31 & 13 & 18 & \\
\hline \multicolumn{15}{|l|}{ Histology } \\
\hline Serous & 53 & 24 & 29 & 0.215 & 23 & 30 & 0.747 & 28 & 25 & 0.761 & 45 & 24 & 21 & 0.598 \\
\hline Others & 12 & 8 & 4 & & 4 & 8 & & 7 & 5 & & 9 & 5 & 4 & \\
\hline \multicolumn{15}{|l|}{ FIGO stage } \\
\hline I-II & 17 & 7 & 10 & 0.574 & 13 & 5 & 0.097 & 7 & 10 & 0.266 & 14 & 7 & 7 & 0.766 \\
\hline III-IV & 48 & 25 & 23 & & 23 & 27 & & 28 & 20 & & 40 & 22 & 18 & \\
\hline \multicolumn{15}{|l|}{ Tumor type } \\
\hline Type I & 15 & 9 & 7 & 0.574 & 10 & 6 & 0.250 & 9 & 7 & 1.000 & 12 & 7 & 5 & 0.755 \\
\hline Type II & 50 & 23 & 26 & & 21 & 28 & & 26 & 23 & & 42 & 22 & 20 & \\
\hline \multicolumn{15}{|l|}{ Chemo response } \\
\hline Sensitive & 46 & 18 & 28 & 0.011 & 27 & 19 & 0.404 & 20 & 26 & 0.053 & 38 & 19 & 19 & 0.363 \\
\hline Resistant & 18 & 14 & 4 & & 8 & 10 & & 13 & 5 & & 15 & 10 & 5 & \\
\hline
\end{tabular}

$3{ }^{*}$ The median IHC score was chosen as the cut-offs for pEZH2, pAkt1 and H3K27Me3. ${ }^{* *}$ Age at surgery. P values were calculated by

4 chi square and Fisher's exact tests. 


\section{Table 2 (on next page)}

Association between EZH2/H3K27Me3 to clinical pathological features in ovarian cancer by IHC-score stratification. 
1 Table 2. Association between EZH2/H3K27Me3 to clinical pathological features in ovarian cancer by IHC-score stratification*.

\begin{tabular}{|c|c|c|c|c|c|c|c|c|c|}
\hline \multirow[t]{2}{*}{$\begin{array}{l}\text { Clinicopathological } \\
\text { Features }\end{array}$} & \multicolumn{2}{|c|}{$\begin{array}{c}\text { EZH2 } 2^{\text {high} /} \\
\text { H3K27Me3 }{ }^{\text {high }}\end{array}$} & \multicolumn{2}{|c|}{$\begin{array}{c}\text { EZH2 }{ }^{\text {high/ }} \\
\text { H3K27Me3 } 3^{\text {low }}\end{array}$} & \multicolumn{2}{|c|}{$\begin{array}{c}\text { EZH2 } 2^{\text {low } /} \\
\text { H3K27Me } 3^{\text {high }} \\
\end{array}$} & \multicolumn{2}{|c|}{$\begin{array}{c}\text { EZH2 } 2^{\text {low } /} \\
\mathrm{H} 3 \mathrm{~K} 27 \mathrm{Me} 3^{\text {low }} \\
\end{array}$} & \multirow[t]{2}{*}{$\mathrm{P}$} \\
\hline & $\mathrm{N}$ & $(100 \%)$ & $\mathrm{N}$ & $(100 \%)$ & $\mathrm{N}$ & $(100 \%)$ & $\mathrm{N}$ & $(100 \%)$ & \\
\hline Age (years) ${ }^{* *}$ & 16 & 100 & 14 & 100 & 13 & 100 & 11 & 100 & 0.312 \\
\hline$<50$ & 9 & 56.25 & 4 & 28.57 & 7 & 53.85 & 3 & 27.27 & \\
\hline$\geq 50$ & 7 & 23.75 & 10 & 71.43 & 6 & 46.15 & 8 & 72.73 & \\
\hline Histology & 16 & 100 & 14 & 100 & 13 & 100 & 11 & 100 & 0.447 \\
\hline Serous & 12 & 75.00 & 12 & 85.71 & 12 & 92.31 & 9 & 81.82 & \\
\hline Others & 4 & 25.00 & 2 & 14.29 & 1 & 7.96 & 2 & 18.18 & \\
\hline FIGO stage & 16 & 100 & 14 & 100 & 13 & 100 & 11 & 100 & 0.537 \\
\hline I-II & 3 & 18.75 & 4 & 28.57 & 4 & 30.77 & 3 & 27.27 & \\
\hline III-IV & 13 & 81.25 & 10 & 71.43 & 9 & 69.23 & 8 & 72.73 & \\
\hline Tumor type & 16 & 100 & 14 & 100 & 13 & 100 & 11 & 100 & 0.682 \\
\hline Type I & 5 & 31.25 & 2 & 14.29 & 2 & 15.38 & 3 & 27.27 & \\
\hline Type II & 11 & 68.75 & 12 & 85.71 & 11 & 84.62 & 8 & 72.73 & \\
\hline Chemo response & 16 & 100 & 13 & 100 & 13 & 100 & 11 & 100 & 0.057 \\
\hline Sensitive & 10 & 62.50 & 8 & 61.54 & 4 & 30.77 & 11 & 100 & \\
\hline Resistant & 6 & 37.50 & 5 & 38.46 & 9 & 69.23 & 0 & 0 & \\
\hline
\end{tabular}

$2{ }^{*}$ The median IHC score was chosen as the cut-offs for pEZH2, pAkt1 and H3K27Me3. ${ }^{* *}$ Age at surgery. P values were calculated by

3 Kruskal-Wallis test. 


\section{Table 3(on next page)}

Association between pAkt1/pEZH2 to clinical pathological features in ovarian cancer by IHC-score stratification. 
1 Table 3. Association between pAkt1/pEZH2 to clinical pathological features in ovarian cancer by IHC-score stratification*.

\begin{tabular}{|c|c|c|c|c|c|c|c|c|c|}
\hline \multirow[t]{2}{*}{$\begin{array}{l}\text { Clinicopathological } \\
\text { Features }\end{array}$} & \multicolumn{2}{|c|}{$\begin{array}{l}\text { pAkt } 1^{\text {high} /} \\
\text { pEZH } 2^{\text {high }}\end{array}$} & \multicolumn{2}{|c|}{$\begin{array}{l}\text { pAkt1 } 1^{\text {high} /} \\
\text { pEZH } 2^{\text {low }}\end{array}$} & \multicolumn{2}{|c|}{$\begin{array}{l}\text { pAkt1 } 1^{\text {low } /} \\
\text { pEZH } 2^{\text {high }}\end{array}$} & \multicolumn{2}{|c|}{$\begin{array}{l}\text { pAkt1 } 1^{\text {low } /} \\
\text { pEZH } 2^{\text {low }}\end{array}$} & \multirow[t]{2}{*}{$\mathrm{P}$} \\
\hline & $\mathrm{N}$ & $(100 \%)$ & $\mathrm{N}$ & $(100 \%)$ & $\mathrm{N}$ & $(100 \%)$ & $\mathrm{N}$ & $(100 \%)$ & \\
\hline Age (years) $)^{* *}$ & 18 & 100.00 & 9 & 100.00 & 14 & 100.00 & 24 & 100.00 & 0.899 \\
\hline$<50$ & 6 & 33.33 & 5 & 55.56 & 7 & 50.00 & 9 & 37.50 & \\
\hline$\geq 50$ & 12 & 66.67 & 4 & 44.44 & 7 & 50.00 & 15 & 62.50 & \\
\hline Histology & 18 & 100.00 & 9 & 100.00 & 14 & 100.00 & 24 & 100.00 & 0.907 \\
\hline Serous & 15 & 83.33 & 8 & 88.89 & 10 & 71.43 & 20 & 83.33 & \\
\hline Others & 3 & 16.67 & 1 & 11.11 & 4 & 28.57 & 4 & 16.67 & \\
\hline FIGO stage & 18 & 100.00 & 9 & 100.00 & 14 & 100.00 & 24 & 100.00 & 0.250 \\
\hline I-II & 2 & 11.11 & 3 & 33.33 & 5 & 35.71 & 7 & 29.17 & \\
\hline III-IV & 16 & 88.89 & 6 & 66.67 & 9 & 64.29 & 17 & 70.83 & \\
\hline Tumor type & 18 & 100.00 & 9 & 100.00 & 14 & 100.00 & 24 & 100.00 & 0.999 \\
\hline Type I & 5 & 27.78 & 1 & 11.11 & 4 & 28.57 & 6 & 25.00 & \\
\hline Type II & 13 & 72.22 & 8 & 88.89 & 10 & 71.43 & 18 & 75.00 & \\
\hline Chemo response & 18 & 100.00 & 9 & 100.00 & 14 & 100.00 & 23 & 100.00 & 0.025 \\
\hline Sensitive & 11 & 61.11 & 8 & 88.89 & 7 & 50.00 & 20 & 86.96 & \\
\hline Resistant & 7 & 38.89 & 1 & 11.11 & 7 & 50.00 & 3 & 13.04 & \\
\hline
\end{tabular}

$2{ }^{*}$ The median IHC score was chosen as the cut-offs for pEZH2, pAkt1 and H3K27Me3. ${ }^{* *}$ Age at surgery. P values were calculated by

3 Kruskal-Wallis test. 
Table 4 (on next page)

Associations of different parameters and chemotherapy response. 
1 Table 4. Associations of different parameters and chemotherapy response.

\begin{tabular}{|c|c|c|c|}
\hline & \multicolumn{3}{|c|}{ Chemotherapy response } \\
\hline & OR & $95 \% \mathrm{CI}$ & $\mathrm{P}$ \\
\hline \multicolumn{4}{|l|}{ Age } \\
\hline$\geq 50$ & 1 & & \\
\hline$<50$ & 1.224 & $0.413-3.747$ & 0.697 \\
\hline \multicolumn{4}{|l|}{ Histology } \\
\hline Non-serous & 1 & & \\
\hline Serous & 2.222 & $0.436-11.324$ & 0.337 \\
\hline \multicolumn{4}{|l|}{ FIGO stage } \\
\hline III-IV & 1 & & \\
\hline I-II & 0.258 & $0.052-1.272$ & 0.096 \\
\hline \multicolumn{4}{|l|}{ Tumor Type } \\
\hline Type II & 1 & & \\
\hline Type I & 0.810 & $0.223-2.945$ & 0.748 \\
\hline \multicolumn{4}{|l|}{ EZH2 expression } \\
\hline High & 1 & & \\
\hline Low & 0.323 & $0.099-1.055$ & 0.061 \\
\hline \multicolumn{4}{|l|}{ pEZH2 expression } \\
\hline High & 1 & & \\
\hline Low & 0.184 & 0.052-0.647 & 0.008 \\
\hline \multicolumn{4}{|l|}{ H3K27Me3 expression } \\
\hline High & 1 & & \\
\hline Low & 0.500 & $0.144-1.741$ & 0.276 \\
\hline \multicolumn{4}{|l|}{ pAkt1 expression } \\
\hline High & 1 & & \\
\hline Low & 0.880 & $0.293-2.641$ & 0.819 \\
\hline \multicolumn{4}{|l|}{ EZH2/H3K27Me3 expression } \\
\hline Others & 1 & & \\
\hline Low EZH2/Low H3K27Me3 & 0.110 & 0.013-0.906 & 0.040 \\
\hline \multicolumn{4}{|l|}{ pAkt1/pEZH2 expression } \\
\hline Others & 1 & & \\
\hline Low pAkt1/Low pEZH2 & 0.260 & $0.066-1.023$ & 0.054 \\
\hline
\end{tabular}

2 


\section{Table 5 (on next page)}

Associations of different parameters and chemotherapy response in serous ovarian cancer. 
1 Table 5. Associations of different parameters and chemotherapy response in serous ovarian cancer.

\begin{tabular}{|c|c|c|c|}
\hline & \multicolumn{3}{|c|}{ Chemotherapy response } \\
\hline & OR & $95 \% \mathrm{CI}$ & $\mathrm{P}$ \\
\hline \multicolumn{4}{|l|}{ Age } \\
\hline$\geq 50$ & 1 & & \\
\hline$<50$ & 1.089 & $0.331-3.577$ & 0.888 \\
\hline \multicolumn{4}{|l|}{ FIGO stage } \\
\hline I-II & 1 & & \\
\hline III-IV & 2.692 & $0.516-14.038$ & 0.240 \\
\hline \multicolumn{4}{|l|}{ Tumor Type } \\
\hline Type I & 1 & & \\
\hline Type II & 2.429 & $0.311-18.986$ & 0.398 \\
\hline \multicolumn{4}{|l|}{ EZH2 expression } \\
\hline High & 1 & & \\
\hline Low & 0.364 & $0.105-1.263$ & 0.111 \\
\hline \multicolumn{4}{|l|}{ pEZH2 expression } \\
\hline High & 1 & & \\
\hline Low & 0.188 & $0.050-0.705$ & 0.013 \\
\hline \multicolumn{4}{|l|}{ H3K27Me3 expression } \\
\hline High & 1 & & \\
\hline Low & 0.417 & $0.106-1.644$ & 0.211 \\
\hline \multicolumn{4}{|l|}{ pAkt1 expression } \\
\hline High & 1 & & \\
\hline Low & 1.029 & $0.314-3.369$ & 0.963 \\
\hline \multicolumn{4}{|l|}{ EZH2/H3K27Me3 expression } \\
\hline Others & 1 & & \\
\hline Low EZH2/Low H3K27Me3 & 0.133 & $0.016-1.133$ & 0.065 \\
\hline \multicolumn{4}{|l|}{ pAkt $1 / \mathrm{pEZH} 2$ expression } \\
\hline Others & 1 & & \\
\hline Low pAkt1/Low pEZH2 & 0.288 & $0.070-1.190$ & 0.086 \\
\hline
\end{tabular}




\section{Table 6(on next page)}

Table 6

Univariate Cox regression survival analysis. 
1 Table 6. Univariate Cox regression survival analysis.

\begin{tabular}{|c|c|c|c|c|c|c|}
\hline & \multicolumn{3}{|c|}{ OS } & \multicolumn{3}{|c|}{ PFS } \\
\hline & HR & $95 \% \mathrm{CI}$ & $\mathrm{P}$ & HR & $95 \% \mathrm{CI}$ & $\mathrm{P}$ \\
\hline \multicolumn{7}{|l|}{ Age } \\
\hline$\geq 50$ & 1 & & & 1 & & \\
\hline$<50$ & 1.224 & $0.573-2.701$ & 0.581 & 1.205 & $0.624-2.328$ & 0.579 \\
\hline \multicolumn{7}{|l|}{ Histology } \\
\hline Non-serous & 1 & & & 1 & & \\
\hline Serous & 1.346 & $0.463-3.909$ & 0.585 & 1.735 & $0.672-4.481$ & 0.255 \\
\hline \multicolumn{7}{|l|}{ FIGO stage } \\
\hline III-IV & 1 & & & 1 & & \\
\hline I-II & 0.118 & $0.016-0.870$ & 0.036 & 0.371 & $0.144-0.955$ & 0.040 \\
\hline \multicolumn{7}{|l|}{ Tumor Type } \\
\hline Type II & 1 & & & 1 & & \\
\hline Type I & 0.790 & $0.316-1.975$ & 0.615 & 0.757 & $0.343-1.668$ & 0.489 \\
\hline \multicolumn{7}{|l|}{ Chemo-response } \\
\hline Resistant & 1 & & & 1 & & \\
\hline Sensitive & 0.088 & $0.035-0.219$ & 0.000 & 0.046 & $0.018-0.114$ & 0.000 \\
\hline \multicolumn{7}{|l|}{ EZH2 expression } \\
\hline High & 1 & & & 1 & & \\
\hline Low & 0.464 & $0.205-1.048$ & 0.065 & 0.586 & $0.300-1.146$ & 0.118 \\
\hline \multicolumn{7}{|l|}{ pEZH2 expression } \\
\hline High & 1 & & & 1 & & \\
\hline Low & 0.464 & $0.206-1.046$ & 0.064 & 0.447 & $0.226-0.882$ & 0.020 \\
\hline \multicolumn{7}{|l|}{ H3K27Me3 expression } \\
\hline High & 1 & & & 1 & & \\
\hline Low & 0.823 & $0.342-1.980$ & 0.664 & 0.707 & $0.345-1.445$ & 0.341 \\
\hline \multicolumn{7}{|l|}{ pAkt1 expression } \\
\hline High & 1 & & & 1 & & \\
\hline Low & 0.985 & $0.443-2.192$ & 0.971 & 1.008 & $0.518-1.963$ & 0.980 \\
\hline \multicolumn{7}{|l|}{ EZH2/H3K27Me3 } \\
\hline Others & 1 & & & 1 & & \\
\hline EZH2 $2^{\text {low }} / \mathrm{H} 3 \mathrm{~K} 27 \mathrm{Me} 3^{\text {low }}$ & 0.257 & $0.076-0.863$ & 0.028 & 0.344 & $0.145-0.813$ & 0.015 \\
\hline \multicolumn{7}{|l|}{ pAkt1/pEZH2 } \\
\hline Others & 1 & & & 1 & & \\
\hline $\mathrm{pAkt} 1^{\text {low }} / \mathrm{pEZH} 2^{\text {low }}$ & 0.561 & $0.224-1.407$ & 0.218 & 0.523 & $0.252-1.086$ & 0.082 \\
\hline
\end{tabular}


Table 7 (on next page)

Table 7

Multivariate Hazard Cox regression survival analysis. 
1 Table 7. Multivariate Hazard Cox regression survival analysis.

\begin{tabular}{|c|c|c|c|c|c|c|}
\hline & \multicolumn{3}{|c|}{ OS } & \multicolumn{3}{|c|}{ PFS } \\
\hline & HR & $95 \% \mathrm{CI}$ & $\mathrm{P}$ & HR & $95 \% \mathrm{CI}$ & $P$ \\
\hline \multicolumn{7}{|l|}{ EZH2 expression } \\
\hline High & 1 & & & 1 & & \\
\hline Low & 0.535 & $0.237-1.209$ & 0.133 & 0.649 & $0.331-1.272$ & 0.208 \\
\hline \multicolumn{7}{|l|}{ pEZH2 expression } \\
\hline High & 1 & & & 1 & & \\
\hline Low & 0.512 & $0.227-1.155$ & 0.107 & 0.453 & $0.229-0.895$ & 0.023 \\
\hline \multicolumn{7}{|l|}{ H3K27Me3 expression } \\
\hline High & 1 & & & 1 & & \\
\hline Low & 1.029 & $0.415-2.555$ & 0.950 & 0.734 & $0.358-1.505$ & 0.399 \\
\hline \multicolumn{7}{|l|}{ pAkt1 expression } \\
\hline High & 1 & & & 1 & & \\
\hline Low & 1.157 & $0.524-2.555$ & 0.718 & 1.115 & $0.571-2.176$ & 0.750 \\
\hline \multicolumn{7}{|l|}{$\mathrm{EZH} 2 / \mathrm{H} 3 \mathrm{~K} 27 \mathrm{Me} 3$} \\
\hline Others & 1 & & & 1 & & \\
\hline $\mathrm{EZH} 2^{\text {low }} / \mathrm{H} 3 \mathrm{~K} 27 \mathrm{Me} 3^{\text {low }}$ & 0.333 & $0.099-1.121$ & 0.076 & 0.388 & 0.164-0.917 & 0.031 \\
\hline \multicolumn{7}{|l|}{ pAkt $1 / \mathrm{pEZH} 2$} \\
\hline Others & 1 & & & 1 & & \\
\hline pAkt1 ${ }^{\text {low }} / \mathrm{pEZH} 2^{\text {low }}$ & 0.547 & $0.219-1.369$ & 0.198 & 0.504 & $0.243-1.049$ & 0.067 \\
\hline
\end{tabular}




\section{Table 8(on next page)}

Table 8

Univariate Cox regression survival analysis of serous ovarian cancer patients. 
1 Table 8. Univariate Cox regression survival analysis of serous ovarian cancer patients.

\begin{tabular}{|c|c|c|c|c|c|c|}
\hline & \multicolumn{3}{|c|}{ OS } & \multicolumn{3}{|c|}{ PFS } \\
\hline & HR & $95 \% \mathrm{CI}$ & $\mathrm{P}$ & HR & $95 \% \mathrm{CI}$ & $\mathrm{P}$ \\
\hline \multicolumn{7}{|l|}{ Age } \\
\hline$\geq 50$ & 1 & & & 1 & & \\
\hline$<50$ & 1.231 & $0.531-2.853$ & 0.628 & 1.134 & $0.558-2.304$ & 0.728 \\
\hline \multicolumn{7}{|l|}{ FIGO stage } \\
\hline III-IV & 1 & & & 1 & & \\
\hline I-II & 0.238 & $0.032-1.802$ & 0.165 & 0.544 & $0.189-1.570$ & 0.260 \\
\hline \multicolumn{7}{|l|}{ Tumor Type } \\
\hline Type II & 1 & & & 1 & & \\
\hline Type I & 0.949 & $0.217-4.145$ & 0.945 & 1.391 & $0.420-4.609$ & 0.589 \\
\hline \multicolumn{7}{|l|}{ Chemo-response } \\
\hline Resistant & 1 & & & 1 & & \\
\hline Sensitive & 0.084 & $0.029-0.237$ & 0.000 & 0.051 & 0.019-0.138 & 0.000 \\
\hline \multicolumn{7}{|l|}{ EZH2 expression } \\
\hline High & 1 & & & 1 & & \\
\hline Low & 0.627 & $0.266-1.480$ & 0.287 & 0.791 & 0.389-1.609 & 0.518 \\
\hline \multicolumn{7}{|l|}{ pEZH2 expression } \\
\hline High & 1 & & & 1 & & \\
\hline Low & 0.482 & $0.201-1.155$ & 0.102 & 0.431 & $0.207-0.896$ & 0.024 \\
\hline \multicolumn{7}{|l|}{ H3K27Me3 expression } \\
\hline High & 1 & & & 1 & & \\
\hline Low & 0.734 & $0.266-2.031$ & 0.552 & 0.645 & $0.295-1.410$ & 0.272 \\
\hline \multicolumn{7}{|l|}{ pAkt1 expression } \\
\hline High & 1 & & & 1 & & \\
\hline Low & 0.866 & $0.364-2.059$ & 0.744 & 0.923 & $0.455-1.876$ & 0.826 \\
\hline \multicolumn{7}{|l|}{$\mathrm{EZH} 2 / \mathrm{H} 3 \mathrm{~K} 27 \mathrm{Me} 3$} \\
\hline Others & 1 & & & 1 & & \\
\hline EZH2 $2^{\text {low }} / \mathrm{H} 3 \mathrm{~K} 27 \mathrm{Me} 3^{\text {low }}$ & 0.379 & $0.111-1.292$ & 0.121 & 0.486 & $0.203-1.163$ & 0.105 \\
\hline \multicolumn{7}{|l|}{$\mathrm{pAkt} 1 / \mathrm{pEZH} 2$} \\
\hline Others & 1 & & & 1 & & \\
\hline $\mathrm{pAkt1} 1^{\text {low }} / \mathrm{pEZH} 2^{\text {low }}$ & 0.498 & $0.182-1.357$ & 0.173 & 0.479 & $0.219-1.046$ & 0.065 \\
\hline
\end{tabular}

